\title{
Editorial JeDEM Vol. 11, No. 1 (2019)
}

\section{Judith Schoßböck and Noella Edelmann}

\author{
Department for E-Governance and Administration, Danube University Krems \\ \{judith.schossboeck, noella.edelmann\}@donau-uni.ac.at
}

Welcome to the new issue of JeDEM comprising the ongoing submissions of research papers and reflections of this year! This issue is another international compilation with the foci Open Data, datadriven e-government, and electronic participation - this time with articles and cases from Asia, Uganda, New England, and Europe.

Open Government Data initiatives are said to play a big role for enhancing trust in governments and as a key enabler of reforms, but more empirical studies are needed to confirm these claims. Cross-country networks and partnerships are on the rise, but we do not know enough yet about how well these are known or how they really impact the lives of people. The paper by Jovito Jose Katigbak's article titled Upgrading the Land Administration System of the Philippines through ICT undertakes a review of an e-government instrument in the area of land administration. An area that is critical for raising the standard of living of the Filipinos is the effective and efficient land administration in an increasingly digital landscape. The Land Registration Authority (LRA) launched the Land Titling Computerization Project (LTCP) in 2008. This research attempts to describe the opportunities and challenges faced by the LTCP by drawing on a descriptive-exploratory method and identifying the depth of e-government development. The study defines the information service level based on the UN Online Service Index for the program and identifies necessary improvements. The paper inter alia demonstrates that advanced e-government countries may serve as an inspiration, but might not represent best models for all countries in their uniqueness, particularly from the perspective of a developing country.

A case from Uganda by Martin Nilsson \& Sirkku Männikkö Barbutiu addresses the implementation of an e-participation system in a low-income region: the Kabarole district in western Uganda. Crucial in this context is also the country's limited access to ICTs and lower awareness of civic rights and responsibilities, proposing several distinct challenges. This requires an understanding of the contextual conditions, which the study provides through a qualitative analysis of the implementation phase of an E-Participation platform for Increased Citizen Engagement. Authors analyse the factors that play key roles in defining access to and use of the system by citizens. Which dimensions would you consider as crucial for successful platform use in this case? Read the paper and find out! 
E-participation platforms provide a good starting point to find out more about human interaction and cognitive processes. The paper Affective Effect: Issue Engagement on a Youth E-Participation Platform by Thomas J. Lampoltshammer, Quinfeng Zhu \& Peter Parycek departs from the idea that emotion plays a big role for decision-making and engagement. Based on data from a cross-country European youth e-participation platform, the effects of emotions in eliciting participation are examined following affective intelligence theory and appraisal theory. Specifically, they utilize text and statistical analysis to examine three types of emotions: anger, anxiety, and sadness. Find out about what young people on the platform got most angry or sad about in the paper!

We present another research paper focusing on Open Data, specifically Open Data Portals in New England. The Case Study by Bonnie Page focuses on proactive release of open data via a central point of access. Specifically, this paper examines state-level open data portals and how the push towards OGD initiated during the Obama administration in the US has been interpreted and implemented. It thus provides a snapshot of some of the difficulties and successes that smaller states experience in creating and maintaining open data portals. And we also find out more about how such initiatives stand following the 2016 change in administration, and whether they are successful in supporting their goals and encouraging long-term access to data.

This issue also includes a reflection by Ebenezer Agboz \& Benjamin Kwesi Asamoah titled Datadriven E-government: Exploring the Socio-economic Ramifications. Authors reflect on the transition towards a data-driven public sector, with the benefits of big data, artificial intelligence and machine learning influencing this change. The reflection outlines results of current research that claim that data-driven e-government policies improve socio-economic development in some nations.

We have been plotting behind the scenes to give JeDEM better indexing, usability, appearance and structure. Do you want to submit a paper on one of the journal topics, have an interesting literature review or analysis that would fit for a reflection in JeDEM? You can submit to any of the paper categories on an ongoing basis, decisions about its publication will be made by the editors before the double-blind peer-review process. We've already been working on ideas to offer a shorter publishing process in the future, and look forward to further enhancing the quality and reputation of JeDEM, while following our online format and staying true to our open access policy with no publishing fees. And did you know that you can also comment on articles and give feedback there?

We hope you enjoy this diverse issue of JeDEM. Good news for 2020: There are more articles in the pipeline - watch our website. And, as from 1. January 2020, we will also start working together with our new chief editor Anneke Zuiderwijk from TU Delft, The Netherlands, something we are particularly looking forward to!

\section{About the Editors}

\section{Judith Schoßböck}

Judith Schoßböck is a researcher at the Centre for E-Governance at Danube University Krems, Austria and a $\mathrm{PhD}$ candidate at the Department for Media and Communication at City University Hong Kong (HKPFS award recipient). She is managing editor of the open access e-journal JeDEM (jedem.org). At Danube University, she was inter alia involved in research projects covering electronic participation, open access, open data and social media and governance. 


\section{Noella Edelmann}

Noella Edelmann completed her Psychology Degree at the University of Strathclyde, UK and Masters' Degrees at the University of London, UK and the Danube University Krems, Austria. She received her PhD from the Tallinn University of Technology, Estonia where she focused on the importance of online lurking in the context e-participation. Currently she is a senior researcher at the Department for Governance and Administration at the Danube University Krems. Her main research interests are the digital transformation and the use of social media in the public sector, e-participation, Open Access and scholarly communication. She is involved in the EU-funded projects such as Gov 3.0, Cap4City, and national projects funded by the Lower Austrian Regional Government, the Austrian Ministry of Digital and Economic Affairs (BMDW) and the Ministry of Civil Service and Sport. Noella is the Managing Editor of the international Open Access eJournal for EDemocracy and Open Government (JeDEM), Chair of the Social Media Track at the EGOV-CeDEM-ePart Conference and a member of IFIP WG 8.5. 